\title{
Thermoanalytical tests (TG-DTG-DSC, Py-GC/MS) of foundry binders on the example of polymer composition of poly(acrylic acid)-sodium carboxymethylcellulose
}

\author{
Beata Grabowska ${ }^{1}$ (i) $\cdot$ Sylwia Żymankowska-Kumon ${ }^{1} \cdot$ Sylwia Cukrowicz ${ }^{1} \cdot$ Karolina Kaczmarska $^{1} \cdot$ \\ Artur Bobrowski ${ }^{1} \cdot$ Bożena Tyliszczak ${ }^{2}$
}

Received: 19 November 2018/Accepted: 1 October 2019/Published online: 7 November 2019

(c) The Author(s) 2019

\begin{abstract}
The results of thermal analysis (TG-DTG-DSC) of a foundry binder from the BioCo group in the form of a polymer composition of poly(acrylic acid)-sodium carboxymethylcellulose (PAA/CMC-Na) are presented in this article. The range of temperature of degradation has been determined. It was found that as the temperature rises, physical and chemical changes take place in the binder as a result of evaporation of solvent water, release of constitutional water, intermolecular dehydration reactions and decomposition of polymer chains with the formation of gaseous decomposition products. Pyrolysis gas chromatography mass spectrometry method (Py-GC/MS) was used to identify PAA/CMC-Na binder degradation products in a predetermined temperature range based on the previously performed thermal analysis of TGDTG-DSC. Py-GC/MS tests were also carried out to determine the emission level of gaseous products of the polymeric binder in the context of the processes occurring in the moulding (foundry) sand, in conditions of its contact with liquid metal. In addition, Py-GC/MS tests were carried out for two commonly used foundry binders based on alkaline phenolic resin cured with esters and based on urea-formaldehyde resin with furfuryl alcohol cured with sulphonic acids. The obtained Py-GC/MS results for commercial binders were referred to the results obtained for the new PAA/CMC-Na binder. It was found that the new polymer binder is characterized by the lowest emission level of gaseous products.
\end{abstract}

Keywords Polymer binders · Foundry sands · Thermal degradation $\cdot$ TG-DTG-DSC $\cdot$ Py-GC/MS

\section{Introduction}

At present, one of the largest groups of foundry sands used for the production of moulds and cores is the moulding sands based on the mineral matrix and bonded with organic binders in the form of synthetic resins. Resins are mixtures of synthetic monomers and polymers with a relatively small degree of polymerization, linear or

Beata Grabowska

beata.grabowska@agh.edu.pl

1 Faculty of Foundry Engineering, AGH University of Science and Technology, Reymonta 23, 30059 Kraków, Poland

2 Department of Chemistry and Technology of Polymers, Faculty of Chemical Engineering and Technology, Cracow University of Technology, Warszawska 24, 31-155 Kraków, Poland branched, in which the composition usually contains phenyl (aromatic) groups. The most commonly used foundry sands bonded with synthetic resins include moulding sands with organic resins, among others phenolic, furfuryl, phenol-formaldehyde (generally mixture of them) or alkyd resins $[1,2]$. The process of cross-linking organic binders in moulding sand is usually carried out at room temperature. At the same time, this process is often aided by the blowing through the binder system of gaseous substances, including $\mathrm{SO}_{2}$ or $\mathrm{CO}_{2}$ and amines. This type of cross-linking has a positive effect on many moulding sand properties, including to increase the bonding rate in the binder matrix system, as well as to reduce energy consumption. On the other hand, the use of synthetic resins is associated with their negative impact on the environment like the presence of harmful organic compounds in their composition or using $\mathrm{SO}_{2}$ or toxic amines in the curing process. In addition, during pouring the mould with a 
liquid metal, harmful products of thermal decomposition of binders are emitted to the atmosphere [2-9].

In foundry process, as organic binders for moulding sands and cores are mainly used polymer binders, which, unlike synthetic resins, contain only synthetic, natural or modified polymers dissolved in a suitably selected solvent. Among the synthetic polymers used in foundries are, among others, polystyrene, polyacrylates and polyurethanes. In the literature, one can find works focusing on the development of adhesives and casting processes using natural polymers, as well as polymers from the so-called renewable sources (including from biomass) [9-13].

At present, in the country and around the world, research is being carried out to obtain binders composed of materials derived from natural, often renewable sources, which is associated with a reduction in production costs, while maintaining good-quality castings. The activities are carried out to create new binders that are environmentally friendly in their original form and do not generate harmful substances in the technological process. It is important to minimize the emission of gaseous products of thermal decomposition during the pouring process of liquid metal [14-18].

Thermal degradation of polymeric materials is a complicated process running in a heterophasic system. Therefore, the choice of the analytical method and determination of measurement conditions is important in the context of the analysis of gaseous products generated during the thermal decomposition process. The control and identification of emissions of gaseous products is also important for environmental reasons, as harmful substances are released on an industrial scale, including $\mathrm{CO}, \mathrm{SO}_{2}, \mathrm{H}_{2} \mathrm{~S}$, aromatic hydrocarbons or dioxins. In order to determine the emission level of gaseous products, numerous research works are carried out using thermoanalytical methods, including coupled methods that combine spectral (MS, IR, Raman) with thermal (TG-DSC) methods. Thermoanalytical techniques enable the combination of thermal analysis methods and analysis of evolved gaseous products using a mass spectrometer (MS) or an infrared spectrometer (IR) in a single measurement [19-23].

Synthetic resins, solvents and organic hardeners used in moulding sands and cores constitute the main source of harmful compounds emission. Emission may occur already at the stage of moulding sand preparation, while volatile organic components, mainly solvents, are released. However, the largest amount of gaseous substances is formed during the contact of the moulding sand with the liquid metal, when under the influence of high temperature thermal destruction of its organic components occurs [24].

The level of gas emissions from moulding sands becomes important in respect of maintaining the safety of work in the foundry, as well as having the final impact on the quality of the casting. Foundry technologies using organic components containing phenyl, amine or sulphur groups in their structure are potentially harmful. The effect on the human body of released amines during the hardening of moulding sands or aromatic hydrocarbons generated during the destruction of the organic components is not indifferent. In addition, the technological and economic aspect should be taken into account, as the gases emitted during the destruction may enter undesirable reactions at the mould-cast interface, which is the reason for many defects of castings, including deterioration of the quality of their surface [25-29].

The research team has been carrying out analytical work for several years, including qualitative and quantitative analysis of gaseous products emitted during the technological process, including the process of pouring the mould with a liquid metal. The measurement method developed in this area using spectral techniques allows to determine the quantity and kinetics of emission of gases emitted, as well as qualitative and quantitative analysis of aromatic hydrocarbons: benzene, toluene, ethylbenzene and xylenes (BTEX) during the pouring process [30]. The research also uses a pyrolysis gas chromatography coupled with mass spectrometry (Py-GC/MS) method to determine the emission level of gaseous substances released in the technological process [31-34].

This paper presents the results of a thermoanalytic cycle research using the thermal methods (TG-DTG-DSC) and pyrolysis gas chromatography coupled with mass spectrometry (Py-GC/MS). The research was aimed at completing the knowledge of the thermal degradation process of a new group of BioCo polymer binders in a given temperature range and at the same time determine the emission level of gaseous substances released during the destruction process. A new polymeric binder from the BioCo group [13, 34-38] was tested, which contained two dissolved in water polymers: poly(acrylic acid) and sodium carboxymethylcellulose. In addition, Py-GC/MS tests were carried out for two popular and commercial binders used in the foundry industry based on alkaline phenolic resin cured with esters and urea-formaldehyde resin with furfuryl alcohol cured with sulphonic acids. Before the binders were sent for testing, they were subjected to a hardening process, because in their hardened form they are degraded in real conditions, i.e. in contact with liquid metal.

\section{Experimental}

\section{Materials}

For the research were used three different binders used in foundry process (with one of innovative and 


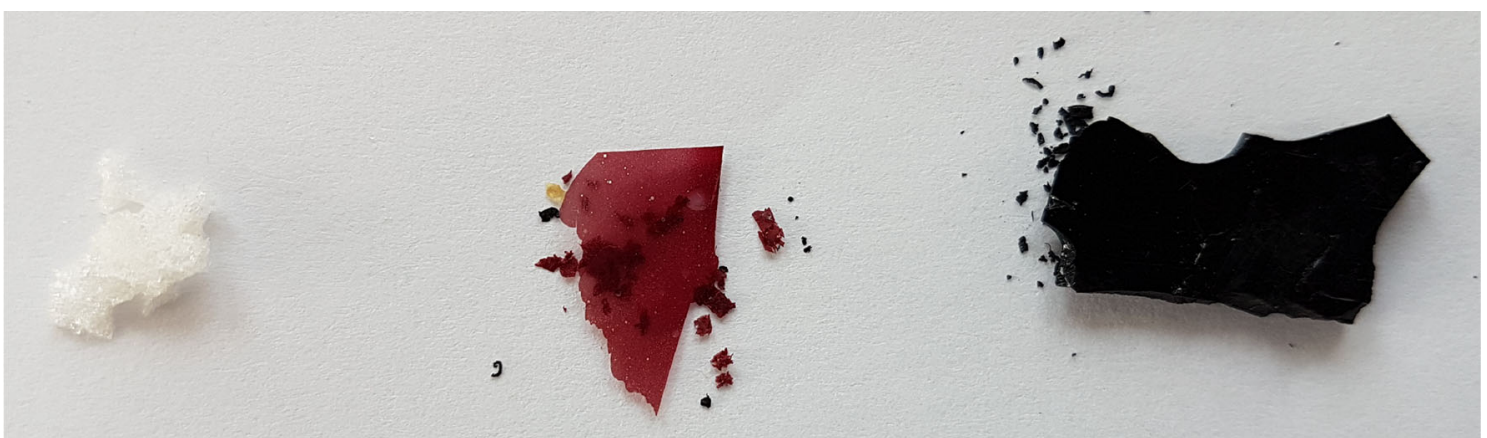

(a)

(b)

(c)

Fig. 1 Samples used in this study: a PAA/CMC-Na, b ARR, c UFR

Table 1 Characteristics of compositions and their cross-linking parameters

\begin{tabular}{ll}
\hline Composition components & Hardening conditions \\
\hline $60 \%$ aqueous solution of poly(acrylic & Microwave device: RM 2001 \\
acid) (PAA, 100 000 g mol ${ }^{-1}$, & Pc, Plazmatronica \\
BASF) and cellulose (CMC-Na, & Microwave power of $800 \mathrm{~W}$ \\
modified cellulose), in a mass ratio & Frequency of $2.45 \mathrm{GHz}$ \\
$7: 8, \mathrm{pH} 2$ & Microwave action time: $60 \mathrm{~s}$ \\
& Temperature inside the \\
& device: $100^{\circ} \mathrm{C}$ \\
\hline
\end{tabular}

environmentally friendly). The samples were prepared in accordance with the manufacturer/inventor's guidelines and according to the appropriate proportions:

1. Polymer composition of poly(acrylic acid)-sodium carboxymethylcellulose (PAA/CMC-Na) (Fig. 1a). Their characterization and cross-linking condition $\mathrm{PAA} / \mathrm{CMC}-\mathrm{Na}$ is provided in Table 1.

2. Alkaline resol resin (ARR)_-alkaline resol type phenolic resin "R" (33-50\% of phenol), liquid binder cured with esters; hardener (activator) " $\mathrm{H}$ "-mixture of organic esters, liquid with a slight characteristic odour and medium curing time (Fig. 1b); proportion of mixture $\mathrm{H}: \mathrm{R}=1: 5$.

3. Urea-formaldehyde resin (UFR)—urea-formaldehyde resin " $R$ " modified by furfuryl alcohol (content of a furfuryl alcohol is about $80 \%$ ); hardened by mixture of sulphonic acid and inorganic acid (Fig. 1c); proportion of mixture $\mathrm{H}: \mathrm{R}=1: 2$.

The most important parameters of binders alkaline resol resin and urea-formaldehyde resin are presented in Table 2.

\section{Thermal examinations}

The thermal examinations were carried out using a Netzsch STA 449 F3 Jupiter ${ }^{\circledR}$ thermal analyser which supports
Table 2 Characterization of components of binders alkaline resol resin and urea-formaldehyde resin

\begin{tabular}{lll}
\hline Parameters & ARR & UFR \\
\hline$R$ & & \\
Density in $20{ }^{\circ} \mathrm{C} / \mathrm{g} \mathrm{cm}^{-3}$ & $1.55-1.65$ & $1.20-1.30$ \\
Viscosity/CST & $15-25$ & $50-150$ \\
Formaldehyde/\% & $0.12-0.14$ & $<0.2$ \\
Nitrogen $/ \%$ & $3-4$ & - \\
Gelation time in $20{ }^{\circ} \mathrm{C} / \mathrm{min}$ & $7-12$ & $11-14$ \\
$H$ & & \\
Density in $20{ }^{\circ} \mathrm{C} / \mathrm{g} \mathrm{cm}^{-3}$ & $1.22-1.24$ & $1.09-1.28$ \\
\hline
\end{tabular}

simultaneous TG and DSC measurements, thus providing two independent signals recorded in the same measurement conditions, namely at/in the same temperature increase rate $\left(10{ }^{\circ} \mathrm{C} \min ^{-1}\right)$ and atmosphere and gas flow rate $\left(50 \mathrm{~mL} \mathrm{~min}{ }^{-1}\right)$. The measurements for the sample were taken in an oxygen-free one (nitrogen). The sample submitted to the TG-DSC thermal analysis weighed approximately $15 \mathrm{mg}$. Crucibles with $\mathrm{Al}_{2} \mathrm{O}_{3}$ were used, as they allowed measurements up to $1000{ }^{\circ} \mathrm{C}$.

\section{Pyrolysis gas chromatography coupled with mass spectrometry}

The pyrolysis gas chromatography mass spectrometry (PyGC/MS) method is based on transforming a solid sample (4 mg) into gas by heating in an atmosphere of inert gas (helium) in a pyrolyzer "Py" (Pyroprobe 5000, CDS Analytical Inc., USA), which is accompanied by thermal decomposition. It has a platinum ribbon, which enables heating of a sample to any temperature within the range $240-1300{ }^{\circ} \mathrm{C}$ at a rate of up to $10,000{ }^{\circ} \mathrm{C} \mathrm{s}^{-1}$. The obtained mixture of compounds (pyrolysate) is separated on a chromatographic column (Rxi-5Sil MS columns, fused silica with low-polarity phase: Crossbond 1,4bis(dimethylsiloxy)phenylene dimethyl polysiloxane, 
Restek Corporation, USA) in a chromatograph "GC" (Focus GC, Thermo Scientific, USA). A temperature programme was applied: an initial temperature of $40{ }^{\circ} \mathrm{C}$ was held for $3 \mathrm{~min}$; ramped $3{ }^{\circ} \mathrm{C} \mathrm{min}{ }^{-1}$ up to $100{ }^{\circ} \mathrm{C}$ and held for $3 \mathrm{~min}$, and then $250{ }^{\circ} \mathrm{C}$ with heating rate $20{ }^{\circ} \mathrm{C} \mathrm{min}{ }^{-1}$ was maintained for $3 \mathrm{~min}$. Carrier gas (helium) flow rate was $1 \mathrm{~mL} \mathrm{~min}^{-1}$ and sample split ratio was $1: 30$. The separated compounds are analysed in a mass spectrometer "MS" (ISQ Thermo Scientific, USA) in the full range $\mathrm{m} / \mathrm{z}$. Electron ionization $(70 \mathrm{eV})$ at a temperature of $250{ }^{\circ} \mathrm{C}$ was applied [36].

\section{Results and discussion}

\section{TG-DTG-DSC analysis}

Figure 2 depicts the temperature-dependent mass change (TG), rate of mass change (DTG) and heat flow rate (DSC) of the polymer mixture PAA/CMC-Na. In total, five mass loss steps of $7.37 \%, 24.03 \%, 8.87 \%, 34.35 \%$ and $10.28 \%$ were observed. The maximal mass loss rates were obtained for the temperatures $138.8^{\circ} \mathrm{C}, \quad 260.6{ }^{\circ} \mathrm{C}, \quad 360.8^{\circ} \mathrm{C}$, $422.4{ }^{\circ} \mathrm{C}$ and $726.2{ }^{\circ} \mathrm{C}$ which can be seen from the DTG signal. In correlation with the mass loss steps, different energetic effects occurred in the DSC signal. Three overlapping endothermic effects with peak temperatures of $151.3{ }^{\circ} \mathrm{C}, 253.0^{\circ} \mathrm{C}, 621.9^{\circ} \mathrm{C}$ and $729^{\circ} \mathrm{C}$ occurred. The fourth mass loss step correlated with an exothermic peak at $413.7{ }^{\circ} \mathrm{C}$ and $492.7^{\circ} \mathrm{C}$.

Fig. 2 TG-DTG-DSC curves of PAA/CMC-Na composition
As the temperature rises, physical and chemical changes occur due to evaporation of the solvent water $\left(20-100{ }^{\circ} \mathrm{C}\right)$ and then of the structural water, and then intermolecular dehydration reactions $\left(100-260{ }^{\circ} \mathrm{C}\right)$. Within this temperature range, mainly reversible processes occur. In the temperature range of $260-360{ }^{\circ} \mathrm{C}$, polymer chains decompose, including the disintegration of side groups and glycoside bonds (from CMC-Na). In the temperature range of $360-700{ }^{\circ} \mathrm{C}$, the polymer compositions decompose with the formation of gaseous products of destruction. The part of moulding sand which has not decomposed to about $900{ }^{\circ} \mathrm{C}$ may contain carbonized carbon. Based on the thermal analysis of TG-DTG-DSC for PAA/CMC-Na, the temperature range $\left(450{ }^{\circ} \mathrm{C}, 700{ }^{\circ} \mathrm{C}, 800{ }^{\circ} \mathrm{C}\right)$ for Py-GC/ MS method was determined for all tested binders.

\section{Py-GC/MS analysis}

Compounds found after pyrolytic decomposition for all studied samples: PAA/CMS-Na, ARR and UFR, are summarized in Tables 3-5. The comparison of the measured mass spectra to the National Institute of Standards Technology database (NIST MS Search 2.0) and own patterns (e.g. benzene, toluene) gave possible types for the released compounds. For some peaks, structural similar compounds (e.g. structural isomers) were found with high quality of probability. Some pyrolysis products which occupy large peak areas in the Py-GC/MS chromatograms (pyrogram, replaceable name) cannot be identified clearly because of the low matching quality in mass library. Resulting products are not decomposed under mild conditions of pyrolysis

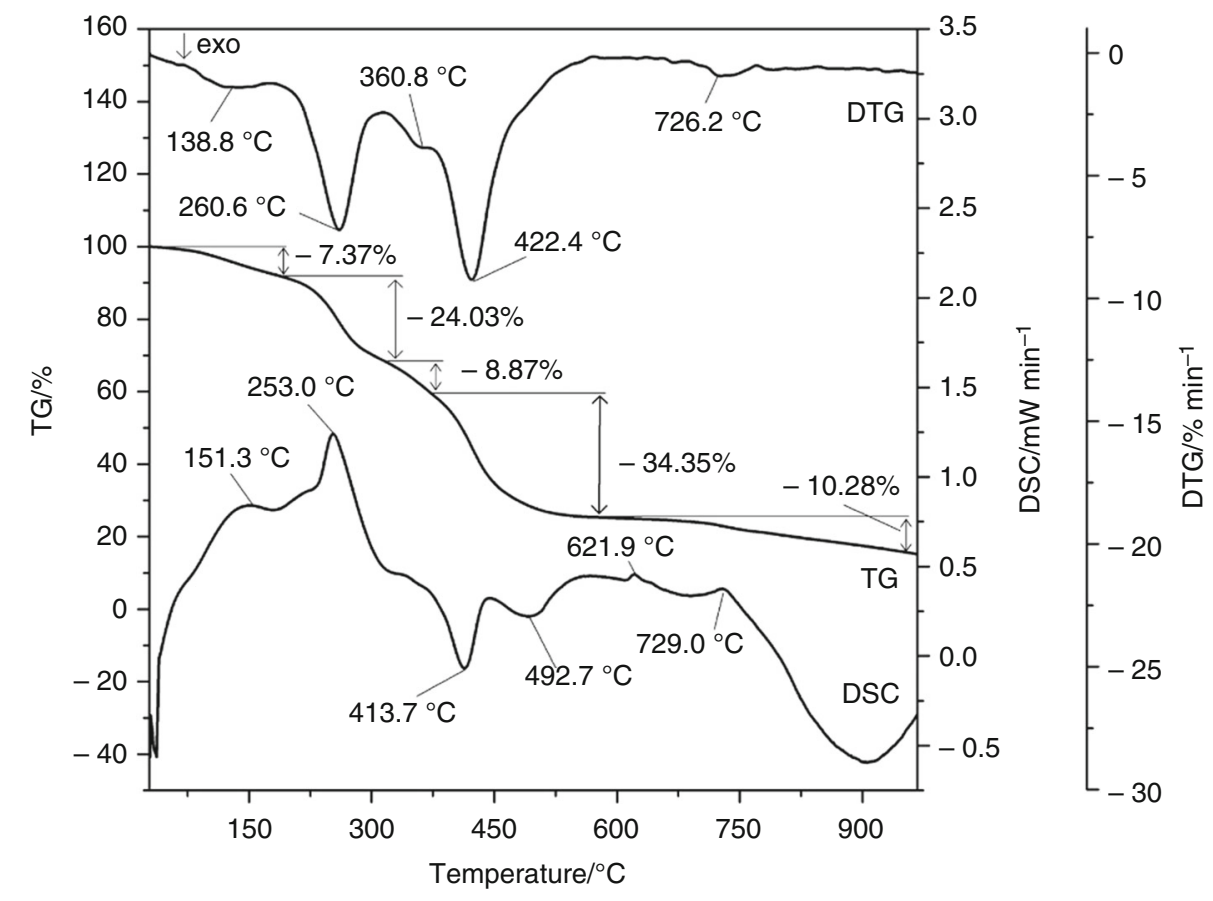


(from 250 to about $400{ }^{\circ} \mathrm{C}$ ); therefore, exemplary chromatograms (pyrograms) in the selected temperature range: $450{ }^{\circ} \mathrm{C}, 700{ }^{\circ} \mathrm{C}$ and $800{ }^{\circ} \mathrm{C}$, are shown in Figs. $3-5$.
The strongest signal in the pyrogram of all tested samples is that corresponding to carbon dioxide emission (full range of temperature, Figs. 3-5). Sample ARR at $700{ }^{\circ} \mathrm{C}$
Table 3 Compounds in the pyrogram of sample PAA/ CMC-Na for selected temperature points/areas

\begin{tabular}{llllllll}
\hline Peak no. & Name of compound & No. CAS & Mass weight/u & \multicolumn{3}{l}{ Retention time $R_{\mathrm{T}} / \mathrm{min}$} \\
\cline { 5 - 7 } & & & $250-650{ }^{\circ} \mathrm{C}$ & $700{ }^{\circ} \mathrm{C}$ & $750{ }^{\circ} \mathrm{C}$ & $800{ }^{\circ} \mathrm{C}$ \\
\hline 1. & Carbon dioxide & $124-38-9$ & 44 & $2-5$ & 2.13 & 2.14 & 2.14 \\
2. & 3-Methylfuran & $930-27-8$ & 82 & - & - & 3.50 & 3.46 \\
3. & Butan-2-one & $78-93-3$ & 72 & - & 3.81 & 3.83 & 3.75 \\
4. & Benzene & $71-43-2$ & 78 & - & - & 4.60 & 4.60 \\
5. & Toluene & $108-88-3$ & 92 & - & - & 7.53 & 7.46 \\
\hline
\end{tabular}

Table 4 Compounds in the pyrogram of sample ARR for selected temperature points/areas

\begin{tabular}{|c|c|c|c|c|c|c|c|c|}
\hline \multirow[t]{2}{*}{ Peak no. } & \multirow[t]{2}{*}{ Name of compound } & \multirow[t]{2}{*}{ No. CAS } & \multirow[t]{2}{*}{ Mass weight/u } & \multicolumn{5}{|c|}{ Retention time $R_{\mathrm{T}} / \mathrm{min}$} \\
\hline & & & & $250-450{ }^{\circ} \mathrm{C}$ & $500-600{ }^{\circ} \mathrm{C}$ & $650-700{ }^{\circ} \mathrm{C}$ & $750{ }^{\circ} \mathrm{C}$ & $800{ }^{\circ} \mathrm{C}$ \\
\hline 1. & Carbon dioxide & $124-38-9$ & 44 & $1.7-2.14$ & 2.10 & 2.09 & 2.11 & 2.10 \\
\hline 2. & 2-Methylfuran & $534-22-5$ & 82 & - & - & 3.38 & 3.38 & 3.34 \\
\hline 3. & Benzene & $71-43-2$ & 78 & - & 4.55 & 4.55 & 4.52 & - \\
\hline 4. & Toluene & $108-88-3$ & 92 & - & 7.46 & 7.40 & 7.43 & 7.32 \\
\hline 5. & Ethylbenzene & $100-41-4$ & 106 & - & 11.49 & 11.49 & 11.49 & - \\
\hline 6. & $m$-Xylene & $108-38-3$ & 106 & - & 11.63 & 11.66 & 11.64 & - \\
\hline 7. & Phenol & $108-95-2$ & 94 & - & 13.45 & 13.51 & 13.51 & - \\
\hline 8. & Styrene & $100-42-5$ & 104 & - & 13.62 & 13.68 & 13.66 & - \\
\hline 9. & Indene & $95-13-6$ & 116 & - & 22.53 & 22.60 & - & - \\
\hline 10. & Naphthalene & $91-20-3$ & 128 & - & 28.99 & 29.03 & - & - \\
\hline 11. & Benzo $[c]$ thiophene & $270-82-6$ & 134 & - & 29,42 & 29.45 & - & - \\
\hline
\end{tabular}

Table 5 Compounds in the pyrogram of sample UFR for selected temperature points/areas

\begin{tabular}{|c|c|c|c|c|c|c|c|c|c|}
\hline \multirow[t]{2}{*}{ Peak no. } & \multirow[t]{2}{*}{ Name of compound } & \multirow[t]{2}{*}{ No. CAS } & \multirow[t]{2}{*}{ Mass weight/u } & \multicolumn{6}{|c|}{ Retention time $R_{\mathrm{T}} / \mathrm{min}$} \\
\hline & & & & $250-400{ }^{\circ} \mathrm{C}$ & $450{ }^{\circ} \mathrm{C}$ & $500-600{ }^{\circ} \mathrm{C}$ & $650-700{ }^{\circ} \mathrm{C}$ & $750{ }^{\circ} \mathrm{C}$ & $800^{\circ} \mathrm{C}$ \\
\hline 1. & Carbon dioxide & $124-38-9$ & 44 & $1.5-2.5$ & 2.11 & 2.10 & 2.10 & 2.09 & 2.11 \\
\hline 2. & Hydrogen sulphide & 7783-06-4 & 34 & - & - & 2.19 & 2.17 & 2.18 & - \\
\hline 3. & Carbon disulphide & $75-15-0$ & 76 & - & - & 2.89 & 2.90 & 2.92 & - \\
\hline 4. & 2-Methylfuran & $534-22-5$ & 82 & - & 3.39 & 3.38 & 3.38 & 3.38 & 3.34 \\
\hline 5. & Benzene & $71-43-2$ & 78 & - & - & 4.55 & 4.54 & 4.52 & - \\
\hline 6. & Toluene & $108-88-3$ & 92 & - & 7.41 & 7.45 & 7.44 & 7.43 & 7.32 \\
\hline 7. & Ethylbenzene & $100-41-4$ & 106 & - & - & 11.46 & 11.50 & 11.49 & - \\
\hline 8. & $m$-Xylene & $108-38-3$ & 106 & - & - & 11.63 & 11.65 & 11.64 & 11.59 \\
\hline 9. & Phenylethyne & $536-74-3$ & 102 & - & - & 13.45 & 13.52 & - & - \\
\hline 10. & Styrene & $100-42-5$ & 104 & - & - & 13.61 & 13.67 & 13.64 & - \\
\hline 11. & Indene & $95-13-6$ & 116 & - & - & 22.53 & 22.60 & - & - \\
\hline 12. & Naphthalene & $91-20-3$ & 128 & - & - & 28.98 & 29.05 & - & - \\
\hline 13. & $\operatorname{Benzo}[c]$ thiophene & $270-82-6$ & 134 & - & - & 29.42 & 29.45 & - & - \\
\hline 14. & Biphenyl & $92-52-4$ & 154 & - & - & 31.60 & - & - & - \\
\hline 15. & Acenaphthylene & $208-96-8$ & 152 & - & - & 32.47 & - & - & - \\
\hline 16. & Bibenzyl & $103-29-7$ & 182 & - & - & - & 32.70 & 32.69 & - \\
\hline
\end{tabular}

Thermal degradation products of chromatographic column 

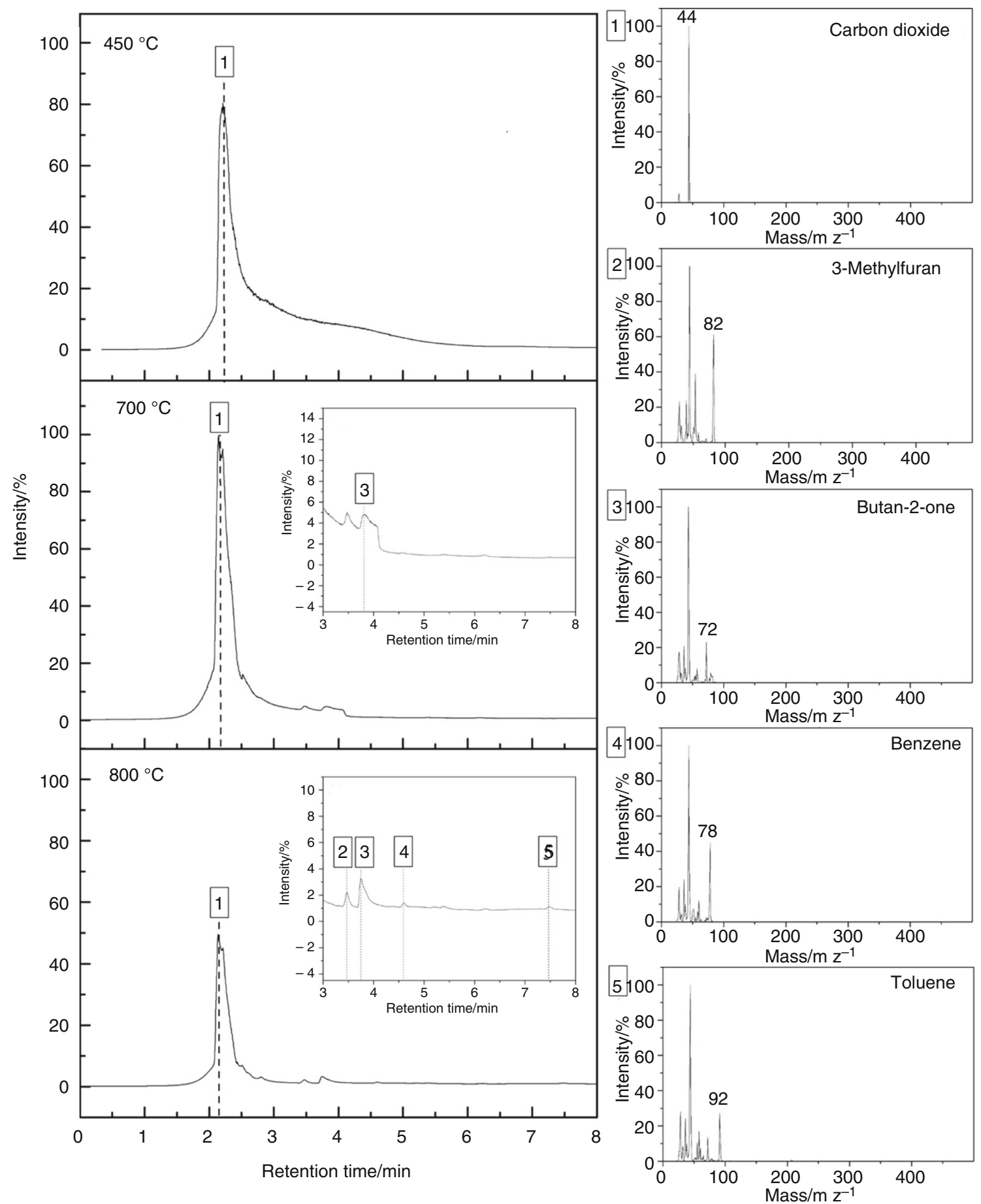

Fig. 3 Pyrograms of sample PAA/CMC-Na in full range of temperature: $450{ }^{\circ} \mathrm{C}, 700{ }^{\circ} \mathrm{C}, 800{ }^{\circ} \mathrm{C}$

observed new small signal from butan-2-one. At the temperature range of $750-800{ }^{\circ} \mathrm{C}$, other new signals correspond to 3-methylfuran, benzene and toluene (Fig. 3). Observed signals (except carbon dioxide) are quite weak, and as a result of pyrolysis, very few compounds are released from the sample (Table 3).
In the pyrograms (Figs. 4, 5) of samples, ARR and UFR are more expanded. Among those identified pyrolysis compounds of samples ARR and UFR, the main signals correspond to large group of aromatic hydrocarbons from groups BTEX and PAH (polycyclic aromatic hydrocarbons). 


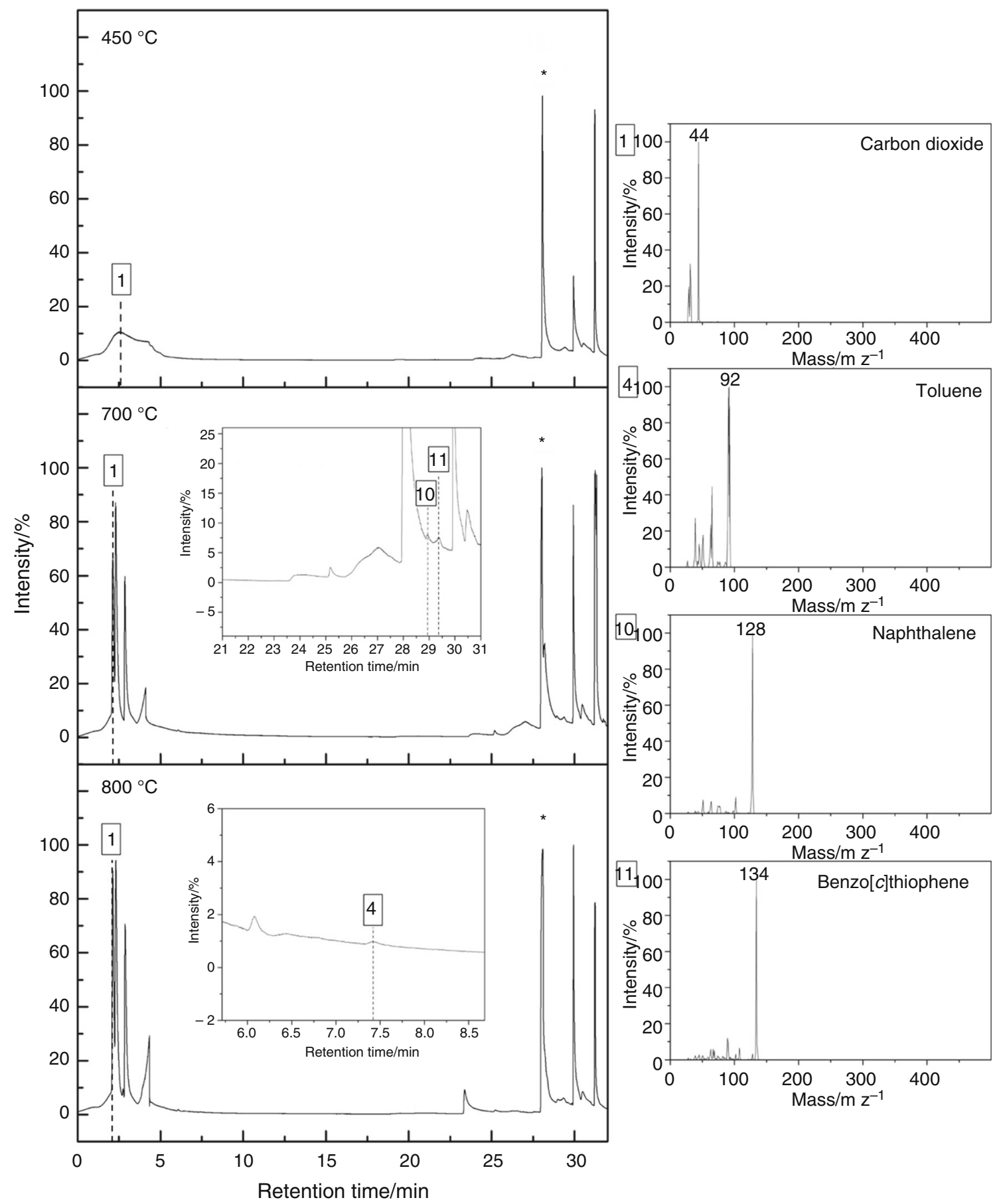

Fig. 4 Pyrograms of sample ARR in full range of temperature: $450{ }^{\circ} \mathrm{C}, 700{ }^{\circ} \mathrm{C}, 800{ }^{\circ} \mathrm{C}$

The decomposition of sample ARR released mainly aromatic hydrocarbons like benzene, phenol and their derivatives and the low-volatile compounds (Table 4). In the temperature range from 250 to $450{ }^{\circ} \mathrm{C}$, no significant changes are observed. The temperature range $500-700{ }^{\circ} \mathrm{C}$ observed a lot of signals from aromatic hydrocarbons group (Fig. 4). The highest signal is from benzene and toluene. Other signals correspond to 2-methylfuran, ethylbenzene, $m$-xylene, phenol (main compound of sample ARR), styrene, indene, naphthalene and benzo[c]thiophene. At $800{ }^{\circ} \mathrm{C}$, most of signals disappeared. (It may be related to their total degradation.) The compounds identified in this sample are connected to chemical composition of thermal decomposition of resole resin [32].

The comparison of the pyrograms samples ARR and UFR did not give significant difference in aromatic 

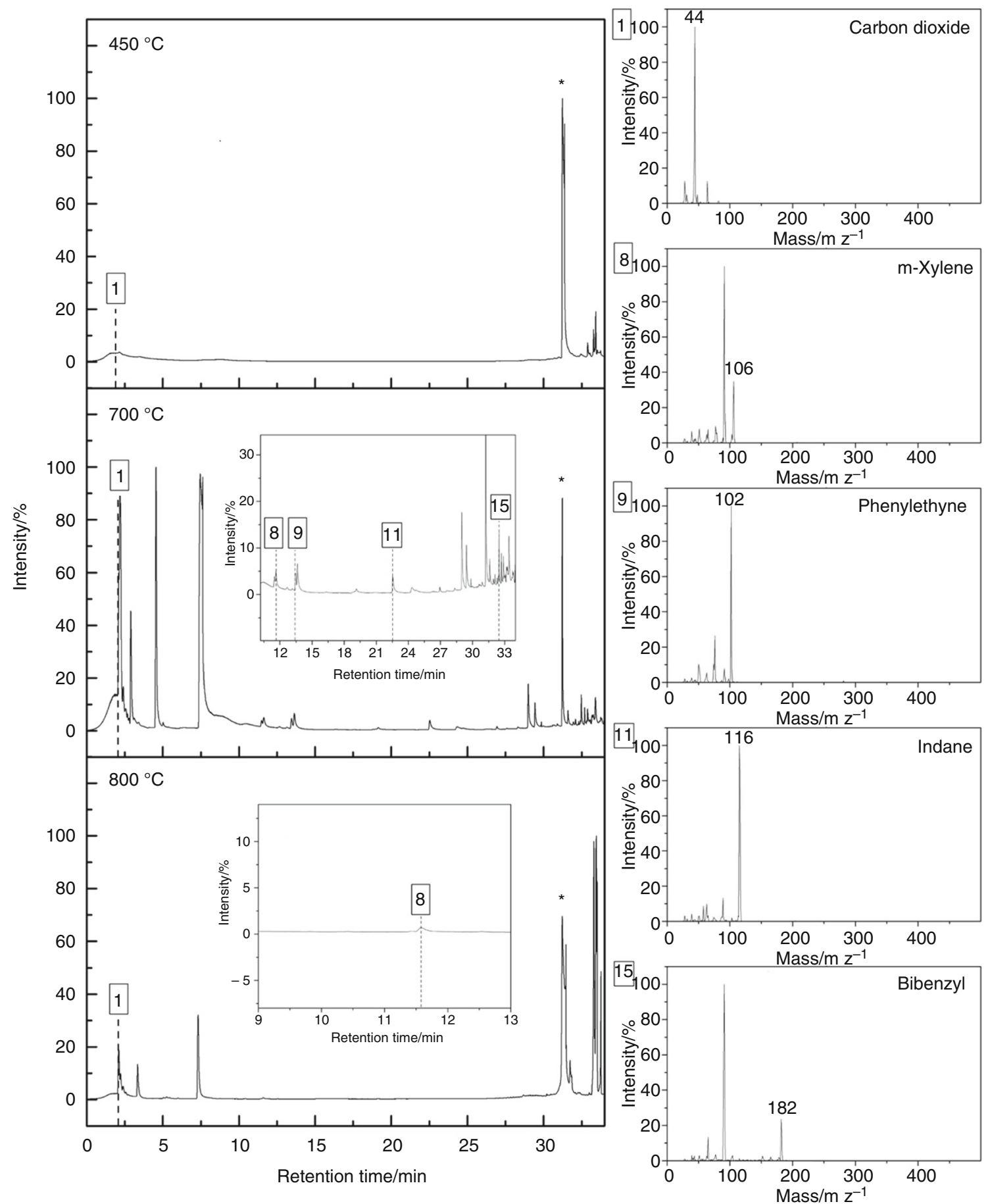

Fig. 5 Pyrograms of sample UFR in full range of temperature: $450{ }^{\circ} \mathrm{C}, 700{ }^{\circ} \mathrm{C}, 800{ }^{\circ} \mathrm{C}$

hydrocarbons area, probably only in concentration of released compound (Table 5). The temperature range $500-700{ }^{\circ} \mathrm{C}$ observed a lot of signals from aromatic hydrocarbons group (Fig. 5) and also compounds like hydrogen sulphide carbon disulphide (component of sample UFR, hardener for resin). The highest signal is from benzene and toluene like in sample ARR. Other signals correspond to similar compounds from sample ARR 2-methylfuran, ethylbenzene, $m$-xylene, styrene, indene, naphthalene and benzo[c]thiophene. A few new ones are also identificated - phenylethyne, biphenyl, acenaphtylene and bibenzyl. At $750{ }^{\circ} \mathrm{C}$ and $800{ }^{\circ} \mathrm{C}$, most of signals disappeared. Only toluene, 2-methylfuran, $m$-xylene are visible.

Py-GC/MS was found to be appropriate method for assessment of changes taking place during pyrolysis of 
tested samples of foundry binders. Results indicate that during the pyrolysis process only one of these samples is friendly to environment (PAA/CMC-Na). The changes in type and emission of these compounds in samples ARR and UFR are small. The presented results of the Py-GC/MS measurements show that the applied analytic methods are feasible to perform only a qualitative characterization of the binder samples (due to the construction of pyrolyzer). In the temperature range up to $450-500{ }^{\circ} \mathrm{C}$, mainly carbon dioxide emissions are observed, related to the decomposition of carbonates (components of tested samples). At the temperature above $500{ }^{\circ} \mathrm{C}$, secreted compounds are mainly volatile aromatics from BTEX and PAH groups or phenol (component of sample ARR). Most of these compounds belongs to group of high risk and pose a threat to humans and the environment. The highest concentration of hazardous and dangerous substances in gas form occurs during the mould pouring with liquid metal (mainly cast iron). Gases emitted to the atmosphere should be neutralized (e.g. scrubbers, filters with active carbon). In addition, it can be concluded that the PAA/CMC-Na polymeric binder is characterized by the lowest emission level of gaseous products in a given temperature range.

\section{Conclusions}

The sample of a foundry binder in the form of a poly(acrylic acid)-sodium carboxymethylcellulose polymer composition has been subjected to thermal analysis of TGDTG-DSC in order to determine the course of its thermal destruction taking into account temperature ranges in which mass losses and gaseous decomposition products occur. It was found that with the temperature rise, there are physical and chemical changes associated with the evaporation of solvent water, release of constitutional water, intermolecular dehydration, and then decomposition of polymer chains with the formation of gaseous products of destruction. On the basis of the thermal analysis for the $\mathrm{PAA} / \mathrm{CMC}-\mathrm{Na}$ polymer composition, the temperature ranges $\left(450{ }^{\circ} \mathrm{C}, 700{ }^{\circ} \mathrm{C}, 800{ }^{\circ} \mathrm{C}\right)$ in which the pyrolysis gas chromatography with mass spectrometry will be performed. In addition, commercial samples of two foundry binders (alkaline resol resin and urea-formaldehyde resin) were included in the study, which allowed to compare their emission levels and the type of gaseous decomposition products.

It was found that the course of degradation with the release of gaseous hydrocarbon products, including BTEX and their derivatives for commercial binders based on ARR and UFR resins, is similar in a given temperature range, with the most signals on pyrograms observed in the 500-700 ${ }^{\circ} \mathrm{C}$ temperature range. The highest signal comes from benzene and toluene for the ARR sample. In the temperature range of $750-800{ }^{\circ} \mathrm{C}$, most of the signals disappear; however, the signal from toluene, 2-methylfuran and $m$-xylene is still visible.

Based on the conducted research, it can be concluded that pyrolysis gas chromatography mass spectrometry method is suitable for assessing the changes occurring during the pyrolysis of foundry binders. In combination with thermal analysis, TG-DTG-DSC gives the possibility of full assessment of emission levels and gaseous products released.

The results obtained indicate that only one of these samples is environmentally friendly during the pyrolysis process. It is a sample of a new polymer binder from the BioCo group (PAA/CMC-Na). The type and emission of gaseous products is small compared to the observed emission level in ARR and UFR samples. The presented results of Py-GC/MS measurements confirm that the applied analytical methods are only able to perform the qualitative characteristics of binder samples. In the lower temperature range of $250-500{ }^{\circ} \mathrm{C}$, mainly $\mathrm{CO}_{2}$ emissions are observed. Above $500{ }^{\circ} \mathrm{C}$, the observed compounds are mainly volatile aromatics from the BTEX and PAH groups, and phenol, which is the main component of the ARR sample.

It is important to note that most of the emitted compounds belong to the high-risk group and pose a threat to people and the environment, with the highest concentration of hazardous and dangerous gaseous substances occurring during casting process. In this context, the obtained knowledge can be the basis for undertaking work on reducing and optimizing the process of neutralizing the gases emitted during casting process, when the mould has the contact with liquid metal.

Open Access This article is distributed under the terms of the Creative Commons Attribution 4.0 International License (http://creative commons.org/licenses/by/4.0/), which permits unrestricted use, distribution, and reproduction in any medium, provided you give appropriate credit to the original author(s) and the source, provide a link to the Creative Commons license, and indicate if changes were made.

\section{References}

1. Kubecki M, Holtzer M, Bobrowski A, Dańko R, Grabowska B, Żymankowska-Kumon S. Analysis of the compounds from the BTEX group, emitted during thermal decomposition of alkyd resin. Arch Foundry Eng. 2012;12:67-72. https://doi.org/10. 2478/v10266-012-0084-z.

2. Patterson MA, Thiel J. Replacement of phenol-formaldehyde in urethane binders. AFS Trans. 2011;119:331-7.

3. Chanda M, Roy Salil K. Industrial polymers, specialty polymers and their applications. 1st ed. Boca Raton: CRC Press; 2008. 
4. Kaczmarska K, Bobrowski A, Zymankowska-Kumon S, Grabowska B. Studies on the gases emission under high temperature condition from moulding sands bonded by modified starch CMSNa. Arch Foundry Eng. 2017;17:79-82. https://doi.org/10.1515/ afe-2017-0014.

5. Fox JR, Adamovits M, Henry C. Strategies for reducing foundry emissions. AFS Trans. 2002;110:1299-309.

6. Scarbel P, Bats CE, Griffin J. Effect of mold and binder formulation on gas evolution when pouring aluminum casting. AFS Trans. 2006;114:435-45.

7. Dungan RS, Reeves JB III. Pyrolysis of foundry sand resins: a determination of products by mass spectrometry. J Environ Sci Health A Tox Hazard Subst Environ Eng. 2005;40:1557-67. https://doi.org/10.1081/ESE-200060630.

8. Dungan RS, Reeves JB 3rd. Pyrolysis of carbonaceous foundry sand additives: seacoal and gilsonite. Thermochim Acta. 2007;460:60-6. https://doi.org/10.1016/j.tca.2007.05.020.

9. Wang J, Jiang H, Jiang N. Study on the pyrolysis of phenolformaldehyde $(\mathrm{PF})$ resin and modified $\mathrm{PF}$ resin. Thermochim Acta. 2009;496:136-42. https://doi.org/10.1016/j.tca.2009.07. 012.

10. Fox JT, Cannon FS, Brown NR, Huang H, Furness JC. Comparison of a new, green foundry binder with conventional foundry binders. Int J Adhes Adhes. 2012;34:38-45. https://doi.org/10. 1016/j.ijadhadh.2011.11.011.

11. Fayomi OSI, Abdulwahab M, Popoola API. Potentials of elaeis guineensis and pinus sylvestris as binders on foundry core strength. J Sci Ind Res. 2014;73:173-6.

12. Zhou X, Yang J, Qu G. Study on synthesis and properties of modified starch binder for foundry. J Mater Process Technol. 2007;183:407-11. https://doi.org/10.1016/j.jmatprotec.2006.11. 001.

13. Grabowska B, Holtzer M, Dańko R, Górny M, Bobrowski A, Olejnik E. New BioCo binders containing biopolymers for foundry industry. Metalurgija. 2013;52:47-50.

14. Patterson M, Thiel J. Replacement of phenol-formaldehyde in urethane binders. AFS Trans. 2011;119:331-7.

15. Zhou X, Yang J, Su D, Qu G. The high-temperature resistant mechanism of $\alpha$-starch composite binder for foundry. J Mater Process Technol. 2009;209:5394-8. https://doi.org/10.1016/j. jmatprotec.2009.04.010.

16. Tiede N, Crepaz R, Eggert T, Bey N. Emission of organic compounds from mould and core binders used for casting iron, aluminum and bronze in sand moulds. J Environ Sci Health A Tox Hazard Subst Environ Eng. 2010;45:1866-76. https://doi. org/10.1080/10934529.2010.520595.

17. Svidró JT, Diószegi A, Svidró J. Thermophysical aspects of reclaimed moulding sand addition to the epoxy- $\mathrm{SO}_{2}$ coremaking system studied by Fourier thermal analysis. J Therm Anal Calorim. 2017;130:1779-89. https://doi.org/10.1007/s10973-0176612-x.

18. Svidró JT, Diószegi A, Svidró J, Ferenczi T. The effect of different binder levels on the heat absorption capacity of moulding mixtures made by the phenolic urethane cold-box process. J Therm Anal Calorim. 2017;130:1769-77. https://doi.org/10. 1007/s10973-017-6611-y.

19. Poljanšek I, Krajnc M. Characterization of phenol-formaldehyde prepolymer resins by in line FT-IR spectroscopy. Acta Chim Slovaka. 2005;52:238-44.

20. Tzeng SS, Chr JG. Evolution of microstructure and properties of phenolic resin-based carbon/carbon composites during pyrolysis. Mater Chem Phys. 2002;73:162-9. https://doi.org/10.1016/ S0254-0584(01)00358-3.

21. Chen Z, Chen Y, Liu H. Pyrolysis of phenolic resin by TG-MS and FTIR analysis. Adv Mater Res. 2013;631-632:104-9.
22. Jiang $\mathrm{H}$, Wang J, Wu S, Yuan $\mathrm{Z}, \mathrm{Hu} \mathrm{Z}$, Wu R, Liu Q. The pyrolysis mechanism of phenol formladehyde resin. Polym Degrad Stab. 2012;97:1527-33.

23. Chang Ch, Tackett JR. Characterization of phenolic resins with thermogravimetry-mass spectrometry. Thermochim Acta. 1991;192:181-90. https://doi.org/10.1016/0040-6031(91)87160$\mathrm{X}$.

24. Bargaoui H, Azzouz F, Thibault D, Cailletaud G. Thermomechanical behavior of resin bonded foundry sand cores during casting. J Mater Process Technol. 2017;246:30-41. https://doi. org/10.1016/j.jmatprotec.2017.03.002.

25. Bates CE, Burch R. Core and mold gas evolution: porosity in castings. Foundry Manag Technol. 2007;135:17-8.

26. Naro RL. Porosity defects in iron castings from mold-metal interface reactions. AFS Trans. 1999;107:839-51.

27. Monroe R. Porosity in castings. AFS Trans. 2005;113:519-46.

28. Winardi L, Littleton HE, Bates CE. Gas pressures in sand cores. AFS Trans. 2007;115:303-12.

29. Scraber P, Bates C, Griffin J. Avoiding gas defects through mold and core package design. Mod Cast. 2006;96:38-40.

30. Patent PL 224705 B1: Station for research of the volume and harmfulness of gases compounds from the materials used in foundry and metallurgical processes.

31. Kusch P. Application of gas chromatography/mass spectrometry (GC/MS) and pyrolysis-gas chromatography/mass spectrometry (Py-GC/MS) in failure analysis in the automotive industry. Eng Fail Anal. 2017;82:726-32. https://doi.org/10.1016/j.engfailanal. 2017.06.033.

32. Lytle CA, Bertscha W, McKinley M. Determination of novolac resin thermal decomposition products by pyrolysis-gas chromatographymass spectrometry. J Anal Appl Pyrolysis. 1998;45:121-31. https:// doi.org/10.1016/S0165-2370(98)00062-X.

33. Zhang H, Zhao H, Zheng K, Li X, Liu G, Wang Y. Diminishing hazardous air pollutant emissions from pyrolysis of furan no-bake binders using methanesulfonic acid as a binder catalyst. J Therm Anal Calorim. 2014;116:373-81.

34. Grabowska B, Sitarz M, Olejnik E, Kaczmarska K, Tyliszczak B. FT-IR and FT-Raman studies of cross-linking processes with $\mathrm{Ca}^{2+}$ ions, glutaraldehyde and microwave radiation for polymer composition of poly(acrylic acid)/sodium salt of carboxymethyl starch—in moulding sands, part II. Spectrochim Acta Part A Mol Biomol Spectrosc. 2015;151:27-33. https://doi.org/10.1016/j.saa. 2015.06.084

35. Łucarz M, Grabowska B, Grabowski G. Determination of parameters of the moulding sand reclamation process, on the thermal analysis base. Arch Metall Mater. 2014;59:1023-7. https://doi.org/10.2478/amm-2014-0171.

36. Grabowska B, Kaczmarska K, Bobrowski A, ŻymankowskaKumon S. TG-DTG-DSC, FTIR, DRIFT, and Py-GC-MS studies of thermal decomposition for poly(sodium acrylate)/ dextrin (PAANa/D) - new binder BioCo3. J Cast Mater Eng. 2017;1:27-32. https://doi.org/10.7494/jcme.2017.1.1.27.

37. Grabowska B, Malinowski P, Szucki M, Byczyński Ł. Thermal analysis in foundry technology. $J$ Therm Anal Calorim. 2016;126:245-50. https://doi.org/10.1007/s10973-016-5435-5.

38. Grabowska B, Hodor K, Kaczmarska K, Bobrowski A, KurletoKozioł Ż, Fischer C. Thermal analysis in foundry technology Part 2. TG-DTG-DSC, TG-MS and TG-IR study of the new class of polymer binders BioCo. J Therm Anal Calorim. 2017;130:301-9. https://doi.org/10.1007/s10973-017-6506-y.

Publisher's Note Springer Nature remains neutral with regard to jurisdictional claims in published maps and institutional affiliations. 